Article

\title{
Insulin Secretion by $\beta$-Cell-Like Cells Derived from Pulp Stem Cells Depends on Augmented Cytosolic Zinc Levels than GABA Levels
}

\author{
Gyuyoup Kim ${ }^{\circledR}$, Man-Kyo Chung $®$ and Eung-Kwon Pae * \\ School of Dentistry, University of Maryland, Baltimore 650 W. Baltimore St. Baltimore, MD 21201, USA; \\ alex@encuragen.com (G.K.); MChung@umaryland.edu (M.-K.C.) \\ * Correspondence: epae@umaryland.edu; Tel.: +801-310-740-6161
}

Received: 3 September 2020; Accepted: 20 October 2020; Published: 24 October 2020

check for updates

\begin{abstract}
Background: Stem cells harvested from human exfoliated deciduous teeth (SHED) are pluripotent and can be differentiated into insulin-secreting $\beta$-cells, i.e., SHED $\beta$-cells. Previously, we showed that zinc upregulates insulin secretion from SHED $\beta$-cells, potentially providing an extra source for insulin. Rationale: In this study, we determined the role of ionotropic $\gamma$-aminobutyric acid $A\left(G A B A_{A}\right)$ receptor in zinc-enhanced insulin secretion from SHED $\beta$-cells. Autocrine/paracrine activation of $\mathrm{GABA}_{\mathrm{A}}$ receptors by GABA elevates calcium influx in pancreatic $\beta$-cells, in which intracellular chloride is maintained at high levels. Method and Findings: Differentiating SHED into SHED $\beta$-cells resulted in an increase in the expression of $\mathrm{GABA}_{A}$ receptor subunits and Zrt-/irt-like protein3 (ZIP3), a zinc uptake transporter. Zinc pretreatment elevated the insulin gene transcription, whereas knockdown of ZIP3 reduced levels of intracellular zinc, and concomitantly reduced insulin secretion by SHED $\beta$-cells. Zinc-pretreated SHED $\beta$-cells exhibited a GABA-induced increase in $\mathrm{Ca}^{2+}$ influx, detected with a ratiometric calcium-sensitive dye, suggesting zinc-mediated regulation of $\mathrm{GABA}_{\mathrm{A}}$ receptors. Conclusion: Our results indicate that elevated levels of zinc and $\mathrm{GABA}_{\mathrm{A}}$ receptors are indispensable for efficient insulin secretion by SHED $\beta$-cells. These findings suggest an opportunity for using SHED $\beta$-cells for treating diabetes.
\end{abstract}

Keywords: $\beta$-cells; insulin; GABA; SHED; zinc

\section{Introduction}

Utilizing autologous stem cells from human exfoliated deciduous teeth (SHED) as an insulin reservoir is an attractive option compared to islet allotransplantation procedures for patients with severe Type 2 diabetes or pancreatic fibrosis in pancreatogenic (Type 3c) forms of diabetes [1]. Properly reserved and seeded SHED $\beta$-cells may provide an ideal $\beta$-cell substitute for treating insulin-deficient diabetes if appropriate immune protective agents are guaranteed [2].

Zinc is acknowledged as an essential ion for various cellular functions, and some specific cell types accumulate a significant amount of zinc in the cytosol. Among these, for example, pancreatic $\beta$-cells may contain zinc at concentrations of 10 to $20 \mathrm{mM}$ [3]. The role of zinc in pancreatic $\alpha$-and $\beta$-cells is not fully understood, although zinc is recognized as a principal ion in glucose homeostasis [4-6]. A recent report suggested that excessive secretion of insulin can deplete zinc in $\beta$-cells, and may distress glucose homeostasis, which may be associated with diabetes $[7,8]$. Although the therapeutic potential of SHED-derived $\beta$-cells, i.e., SHED $\beta$-cells, has been suggested, mechanisms explaining the effect of zinc on calcium influx during insulin secretion by SHED $\beta$-cells are not clear.

We previously reported a significant role of elevated zinc levels in the cytosol of primary $\beta$-cells harvested from rats, [9] as well as in pancreatic $\beta$-cell-like cells derived from SHED [10]. In the 
previous study, we showed that insulin secretion levels by rat pancreatic $\beta$-cells and SHED $\beta$-cells increased as cytosolic zinc levels increased. Since recent reports [11-13] suggested a remedial effect of $\gamma$-aminobutyric acid (GABA) on the regeneration of pancreatic cells, we postulated that there could be mutual influence between GABA and intracellular zinc in SHED $\beta$-cells. In this new report, we sought to investigate the relationship between GABA and zinc levels.

GABA is an important and ubiquitous transmitter involved in $\beta$-cell signaling pathways that regulate autocrine/paracrine functions associated with insulin secretion $[13,14]$. GABA $A_{A}$ receptors function as chloride channels in the plasma membrane of $\beta$-cells. Since $\beta$-cells maintain high concentrations of intracellular chloride, GABA induces membrane depolarization resulting in calcium influx, influencing the proliferation of $\beta$-cells [15]. GABA has been thought to ameliorate diabetic symptoms [16,17]. Despite accumulated knowledge, the interactions between GABA and zinc in insulin secretion are not fully understood [18]. Furthermore, it is important to understand whether exogenous GABA supplementation can potentially be utilized as an inducer of GABA-mediated insulin secretion in SHED $\beta$-cells for therapeutic use.

Members of the SLC39A family of zinc transporters, including Zrt/irt-like protein (ZIP)8, facilitate movement of zinc ions from extracellular spaces or intracellular organelles to the cytosol of $\beta$-cells, as we and others have reported [19]. However, most research on zinc transporters and diabetes has been focused on zinc exporters, particularly ZnT8 [20]. In the current study, we have investigated the possibility that the ZIP3 transporter is a functional regulator of intracellular zinc levels in SHED $\beta$-cells, as shown previously for pancreatic $\beta$-cells [6]. We sought to investigate if ZIP3 could be another principal zinc uptake transporter in addition to ZIP8 in SHED $\beta$-cells. Further, we examined the effects of increased zinc levels in the cytosol on insulin secretion and on GABA-induced activation in SHED $\beta$-cells. We hypothesized that the ZIP3 transporter is a principal zinc uptake transporter, which collaborates with GABA in SHED $\beta$-cells for insulin secretion. As an initial step, we determined the expression of Zip3 in the plasma membrane of rodent $\beta$-cells and, following, in SHED $\beta$-cells. Then, we examined whether supplemental zinc enhanced GABA-induced $\mathrm{Ca}^{2+}$ increases in SHED $\beta$-cells.

\section{Materials and Methods}

\subsection{Differentiation of SHED $\beta$-Cells}

First, dental pulp tissue extracted from exfoliated deciduous teeth was dissolved in cold saline. Then, SHED cell culture was initiated in $\alpha$-minimum essential media (Invitrogen, Carlsbad, CA, USA) supplemented with 10\% fetal bovine serum (Invitrogen), $5 \mu \mathrm{g} / \mathrm{mL}$ gentamicin sulfate (Gemini Bio-Products, West Sacramento, CA, USA), and $20 \mathrm{mmol} / \mathrm{L} \mathrm{l-glutamine} \mathrm{(Invitrogen).} \mathrm{SHED}$ cells were amplified to passage 5 in the media, and then were differentiated to SHED $\beta$-cells using a previously established protocol and specific media [10]. SHED cells from deciduous dental pulp proliferate as an adherent monolayer, which cluster into spherical aggregates of cells when transferred to non-adherent tissue culture conditions, as previously shown. We followed the previously published differentiation protocol faithfully [21]. On Day 10 of growth in non-adherent conditions to induce islet-like cellular aggregates (ICA), the majority of SHED ICA stained weakly positive with dithizone. Day-10 SHED $\beta$-cells were supplemented as needed with $100 \mu \mathrm{M}$ GABA and $50 \mu \mathrm{M}$ zinc.

\subsection{Isolation of Rodent-Islets}

We used rat $\beta$-cells for detecting functional Zip3 zinc uptake transporters. First, we isolated islets as previously described. Shortly, cold collagenase solution was injected through the common bile duct. Pancreatic tissue separated from fat tissue was placed into conical tube for digestion at $37^{\circ} \mathrm{C}$ for $8 \mathrm{~min}$ in collagenase, followed by two-times washing using G-solution (1\% BSA containing Hank's balanced salt solution) to dilute collagenase which slows down the digestive process. Then, the tissue was filtered through a Netwell Insert $500 \mu \mathrm{m}$ Polyester Mesh (Corning Inc. NY, USA). The flow-through was centrifuged at $1000 \mathrm{rpm}$ for $2 \mathrm{~min}$, and the pellet was re-suspended with Histopaque 1100 solution 
(1077 and 1119 mixed; Sigma-Aldrich, MO, USA,) for gradient separation by centrifuging at $1200 \mathrm{rpm}$ for $20 \mathrm{~min}$. The supernatant was transferred into a new tube and re-suspended and centrifuged in G-solution twice. The pellet containing islets was re-suspended in RPMI 1640 media (Mediatech Inc., VA, USA), supplemented with $10 \%$ FBS and $1 \%$ Penicillin-Streptomycin mixture and cultured at $37^{\circ} \mathrm{C}$ and $5 \% \mathrm{CO}_{2}$ incubator for $4 \mathrm{~h}$ to allow production of insulin and C-peptide.

\subsection{Immunofluorescence Assay}

Islets were cultured in the Lab-Tek Chamber Slides (Thermo-Fisher Scientific Inc., NY, USA) which were pre-coated with CELL-TAK adhesive (Cat\#354240, Becton Dickinson Bioscience, MA, USA) for $24 \mathrm{~h}$ to allow proper attachment on the surface, and then fixed in CytoCell Fixative solution (Cat\# CF001 L, Biocare Medical, CA) for 20 min. After 15 min blocking with CAS-BLOCK (Cat\# 00-8120, Invitrogen, MD, USA), islets were stained with anti-ZIP3 antibody (Abcam, \#ab117568) and anti-pan-Cadherin antibody (Abcam, \#mAbcam2274) at room temperature for $2 \mathrm{~h}$. After washing with PBS for three times, Alexa Fluor 488-and 594-conjugated secondary antibodies (Cat\# A11029, A11012, respectively, Invitrogen) staining was performed for $1 \mathrm{~h}$. The slides were mounted in Vectashield mounting medium (Cat\# H-1500, Vector Laboratories) with DAPI (Vector Laboratories, CA, USA). Digital images of samples were obtained using the Zeiss LSM 510 META Confocal Microscope (Carl Zeiss, NY, USA).

\subsection{Western Blot Assays}

Collected islets were prepared for whole-cell lysate using RIPA containing protease inhibitors. Cytosolic and plasma membrane fractions were prepared in accordance with the manufacturer's instructions using a subcellular protein fractionation kit (Cat\#78840, Pierce Biotechnology Inc., IL, USA), as previously published [9]. Shortly, cellular compartments were sequentially extracted by incubating cells with cytoplasmic extraction buffer (CEB) followed by membrane extraction buffer (MEB) and nuclear extraction buffer (NEB). Adding micrococcal nuclease (MNase) to NEB extracts chromatin-bound proteins from the cell pellet before adding the pellet extraction buffer (PEB) to solubilize cytoskeletal proteins. Thirty $\mu \mathrm{g}$ of proteins was resolved on the SDS-PAGE on 8-18\% Tris-Glycine gels and transferred onto a PVDF membrane using an electroblotting method. After blocking with $3 \%$ milk TBS-T, the membrane was stained with primary antibodies (anti-ZIP3 and anti-Pan-Cadherin antibodies; anti- $\beta$-actin antibody, \#4970 and anti-MEK1/2 antibodies, \#9122 from Cell Signaling Technology) followed by a horseradish peroxidase-conjugated secondary antibody. Chemiluminescent detection reagents (Pierce Biotechnology Inc., IL, USA) were used to detect immunoreactive proteins and exposed to X-ray films. Density measurements were carried out by Multi Gauge v3.0 (Fujifilm, Japan), and relative values were calculated on the subtracted quantities between ZIP3 and $\beta$-actin bands.

\subsection{RNA Interference}

Harvested SHED islets were transfected with short interfering RNA (siRNA) for rat Slc39a3 (Zip3) or with scrambled siRNA (Cat\# i062238, LV015-G, Applied Biological Materials Inc.) to silence the human ZIP3 mRNA. The sequences were: Slc39a3-36, GGT GGG TGT GTT CTT CTT CAT GCT GCT GG; Slc39a3-129, CCT CTC CCT CTG TAA CAC CTT TGG GGG TG; Slc39a3-286, TTC CTC ACT GTG TTC GTG GAG CAG CTG GT; Slc39a3-877, AGC GAG CAG CTG CTG AAG GTG CTG TTC CT. Transfection was performed using X-tremeGENE siRNA transfection reagent (Cat\# 04476093001, Roche Applied Science) in accordance with the manufacturer's protocol.

\subsection{Real-Time $q R T-P C R$ Assays}

We previously reported the quantification of specific RNAs in differentiated SHED $\beta$-cells by qRT-PCR [10]. We evaluated the expression levels of GABA $A_{A}$ receptors in SHED Day-5 and Day-10 ICAs using the following primers (See Table 1): 
Table 1. Primer sequences used for quantitative RT-PCR.

\begin{tabular}{|c|c|c|}
\hline $\mathrm{GABA}_{\mathrm{A}} \alpha \mathbf{1}$ & F: 5'GCC TCA GCT AAA AGC CCC CAC A; & R: 5'TGC TTT GCT CCA GAC TGC CAG A \\
\hline $\mathrm{GABA}_{\mathrm{A}} \alpha 2$ & F: 5'TGC AAC CAC GCC AGA ACC CAA; & R: 5'TGG CTG TTT TCG CAT GGA GTG CTT \\
\hline $\mathrm{GABA}_{\mathrm{A}} \alpha 3$ & F: 5'TGC ACT CTG CCC GCT GCA AAA; & R: 5'AGG TGG CAC GCA GGA TCA CA \\
\hline $\mathrm{GABA}_{\mathrm{A}} \alpha 6$ & F: 5'TTG AAT AGC TTG CGG CCA GGA CAA; & R: 5'TTT GCC CAC ACA TGC TTA CGG A \\
\hline GLUT2 & F: 5'CCG CTG AGA AGA TTA GAC TTG G; & R: 5'GAC TAG CTC CTG CCT GTT TAT T \\
\hline INS1 & F: 5'CTG GAG AAC TAC TGC AAC TAG AC; & R: 5'TGC TGG TTC AAG GGC TTT AT \\
\hline ZIP3 & F: 5'CAG TCC CAT GTC ATG CAG AG & R: 5'GGA GCT CAA GGA ACA GGT CA \\
\hline
\end{tabular}

Quantitative PCR reactions were performed in triplicate for each sample using the Eppendorf Realplex System (Eppendorf, Hamburg, Germany). The threshold cycle (Ct) for each reaction was normalized $\left(\Delta \mathrm{C}_{\mathrm{T}}\right)$ by the value of the $\beta$-actin (ACTB) housekeeping gene, as we have previously reported [10].

\subsection{Zinc Assay}

Levels of cytosolic zinc were quantified using a Zinc Assay Kit (Cat\# K387-100, BioVision Inc.) in accordance with the manufacturer's protocol, as previously reported [10]. Cell lysates $(50 \mu \mathrm{g})$ were de-proteinized by addition of 7\% TCA solution, and the supernatants were mixed with the zinc reagent in 96 well-plates. Absorbance was estimated at $560 \mathrm{~nm}$ on an Epoch spectrophotometer (BioTek Instruments Inc. Winooski, VT, USA).

\subsection{ELISA Assay}

Insulin levels secreted by stimulated SHED $\beta$-cells were quantified using an insulin ELISA Kit (Cat\# EZRMI-13K, EMD Millipore Corporation) in accordance with the manufacturer's protocol. A total of 10 vials of cell culture media were collected and centrifuged for $5 \mathrm{~min}$ at $3000 \mathrm{rpm}$. The samples were incubated in anti-Insulin Ab-coated plates for $2 \mathrm{~h}$. The plates were then incubated with an HRP-conjugated anti-insulin antibody. Color was developed using $\operatorname{TMB}\left(3,3^{\prime}, 5,5^{\prime}\right.$-tetramethylbenzidine) substrate, and stopped with $100 \mu \mathrm{L}$ Stop solution. Absorbance was measured at $450 \mathrm{~nm}$ using a spectrophotometer.

\subsection{Ratiometric Calcium Imagimolecular Weight ng}

Ratiometric $\mathrm{Ca}^{2+}$ imaging analysis was performed as described previously [22,23]. Dissociated SHED $\beta$-cells were loaded with Fura2-AM (Molecular Probes) for 40 min at $37^{\circ} \mathrm{C}$ in a calcium imaging buffer (CIB) containing $130 \mathrm{mM} \mathrm{NaCl}, 3 \mathrm{mM} \mathrm{KCl}, 0.5 \mathrm{mM} \mathrm{MgCl}_{2}, 0.9 \mathrm{mM} \mathrm{CaCl}_{2}, 10 \mathrm{mM}$ HEPES, $10 \mathrm{mM}$ sucrose, $1.2 \mathrm{mM} \mathrm{NaHCO}_{3} \mathrm{pH} 7.45$, and $320 \mathrm{mOsm}$ (adjusted with mannitol). Ratiometric $\mathrm{Ca}^{2+}$ imaging was performed using an inverted fluorescence microscope (Nikon Instrument) with an excitation filter changer (Sutter Instrument) and a CCD camera (Nikon Instrument) at room temperature. After a 15-min incubation period for de-esterification, the coverslips containing the cells were placed in a recording chamber, which was continuously perfused with CIB with or without drugs. Dual images (510 $\mathrm{nm}$ emission) were collected every $2 \mathrm{~s}$ using NIS Elements (Nikon Instrument). The Fura response was defined as the ratio of emissions measured during excitation at 340 and $380 \mathrm{~nm}$, and the relative Fura response was defined as the ratio normalized to the baseline Fura ratio. To assess the amplitude of changes in the relative Fura ratio ( $\Delta$ response) in each exogenous application, baseline Fura ratios were calculated prior to stimulation, and the percent increase in the relative Fura ratio was calculated.

\subsection{Statistical Analysis}

Statistical analyses were performed with SPSS v. 23; $p<0.05$ was considered significant. For group comparisons between subgroups (e.g., control vs. siRNA-treated), $t$-tests with Bonferroni correction for multiple comparisons were performed as needed. Otherwise, one-way ANOVA was performed. All error bars denoted in each figure indicate SEM. 


\section{Results}

\subsection{Zip3 Zinc Uptake Transporters Reside in the Plasma Membrane of Rodent $\beta$-Cells}

The immunofluorescence (IF) assay visualized pancreatic islets. RNA knockdown tactics and IF assay results demonstrate that Zip3 transporters are in the plasma membrane in the $\beta$-cells isolated from the harvested islets (Figure 1A). The composite pictures were taken at the same setting with $4.89 \mathrm{~s}$ exposure time, 1.5 gain, and -904 offset at $\times 400$ magnification. Figure $1 \mathrm{~A}$ shows both pan-Cadherin protein (green)-containing plasma membrane and Zip3 proteins in blue color. The merged picture of control (SCR or scrambled) $\beta$-cells shows brightened spots aligned along the plasma membrane (see arrowheads in Figure 1A), while siRNA-treated cells show faintly stained cells. Western blot assays on fractionated cells localize ZIP3 transporters clearly. As indicated, Zip3 protein presents in the cell membrane, as shown in Figure 1B-D.

A.
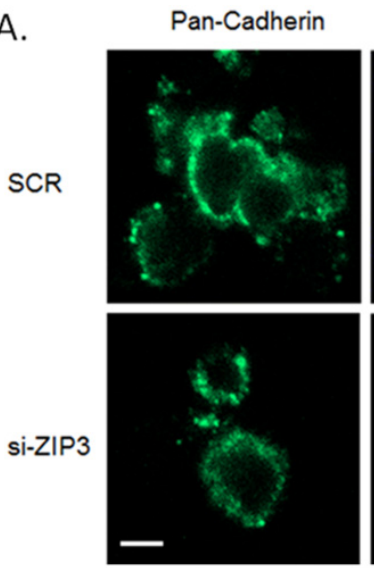

B.

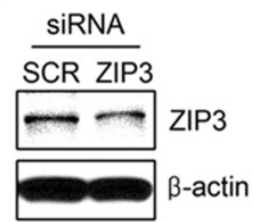

ZIP3
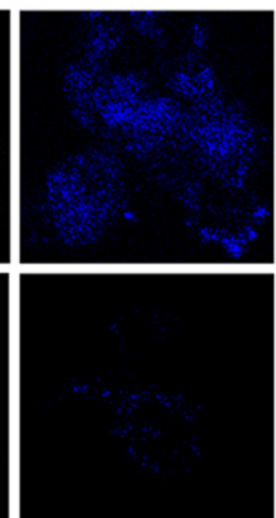

D.

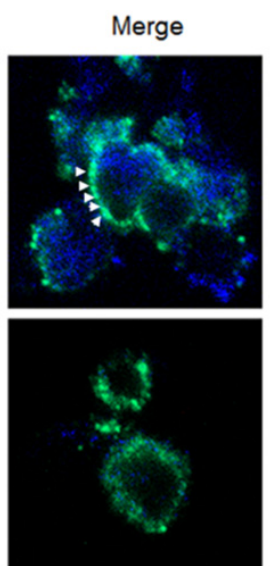

Cytosol Membrane
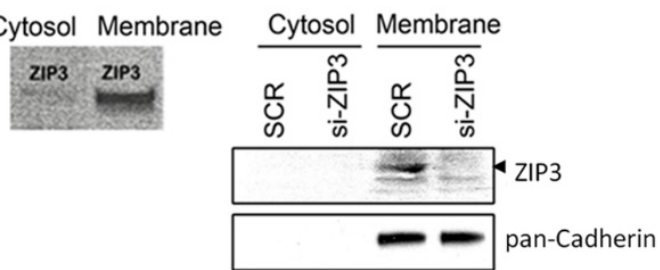

Figure 1. Zip3 protein expressions in rat $\beta$-cells. (A) Zip3 proteins (see arrowheads) are evident in the cell membrane at $\times 400$ magnification. Magnification ruler indicates $5 \mu \mathrm{m}$. (B) Western blot assay results on the whole cells harvested from control (scrambled or SCR) $\beta$-cells and the $\beta$-cells with siRNA-mediated Zip3 knockdown. (C) When fractionated into cytoplasm and plasma membrane portions, Zip3 protein is expressed in the plasma membrane more than the cytoplasm portion. (D) Pan-Cadherin protein clearly reveals that Zip3 resides in the membrane. ZIP3 with arrowhead approximates the position of Molecular Weight 34.

3.2. GABA $A_{A}$ Receptors and ZIP3 Transporter $m R N A$ Levels Increase during Differentiation of SHED into SHED $\beta$-Cells

Real-time qRT-PCR assays were used to analyze maturational changes in the mRNA expression levels of four $\mathrm{GABA}_{\mathrm{A}}$ receptor subunits. Day-10 mRNA levels for $\mathrm{GABA}_{\mathrm{A}} \alpha 1$ receptors (7.2-fold), $\mathrm{GABA}_{\mathrm{A}} \alpha 2$ (7.6-fold), GABA $\alpha 3$ (2.3-fold), and GABA $\alpha 6$ (4.3-fold) receptors were increased relative to $18 \mathrm{~S}$ ribosomal RNA compared to Day 0 (Figure 2A). The expression levels of these receptors in Day-10 SHED were significantly higher than in Day-5 SHED ( $p<0.0001$ indicated by ** in Figure 2A). The expression levels of ZIP3 mRNA also increased at Day 5 and Day $10(p<0.01$ * in Figure 2B) during differentiation of SHED $\beta$-cells. Note that supplementation with $50 \mu \mathrm{M}$ zinc to the cell medium of Day-10 ICAs increased ZIP3 mRNA levels only slightly $(p>0.05)$. 


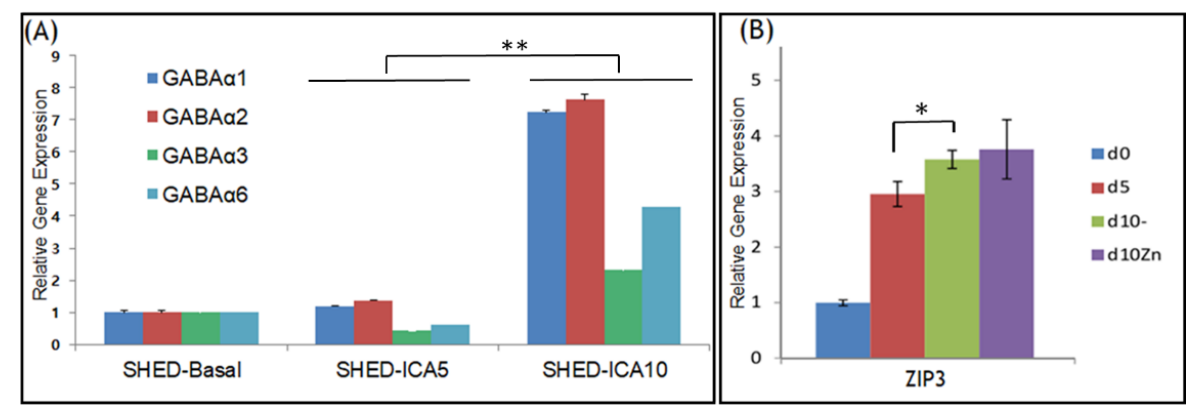

Figure 2. Relative mRNA levels of $\mathrm{GABA}_{\mathrm{A}}$ receptors $\alpha 1, \alpha 2, \alpha 3$, and $\alpha 6$ (A) and ZIP3 transporters (B) relative to $18 \mathrm{~S}$ ribosomal RNA in stem cells from human exfoliated deciduous teeth (SHED) cells as they mature into insulin-producing and -secreting SHED $\beta$-cells. ${ }^{*} p<0.01,{ }^{* *} p<0.0001$.

\subsection{ZIP3 Transporters in the Plasma Membrane of SHED $\beta$-Cells Are Functional}

mRNA levels for Glucose transporter 2 (GLUT2) and Insulin precursor 1 (INS1) increased as SHED $\beta$-cells matured (Figure 3A). Supplementation with zinc significantly increased the expression of GLUT2 and INS1. Results of Western blot analysis indicated that ZIP3 transporters were present in the plasma membrane (Figure 3B). Using siRNA, we confirmed that ZIP3 transporters in the plasma membrane were functional. Results of ELISA assays for insulin levels and zinc contents indicated that siZIP3 partially reduced insulin secretion by SHED $\beta$-cells. Intracellular zinc concentrations showed a significant decrease in ZIP3 siRNA transfectants compared to SCR (scrambled) transfectants (Figure 3C). In the same culture, the amount of insulin secreted into the medium was also significantly reduced in the siZIP3 transfectants compared with the SCR transfectants (Figure 3D). These results suggest that insulin production by SHED $\beta$-cells may depend on the zinc concentration in the cytosol as well as the total amount of ZIP3 protein in the cells.
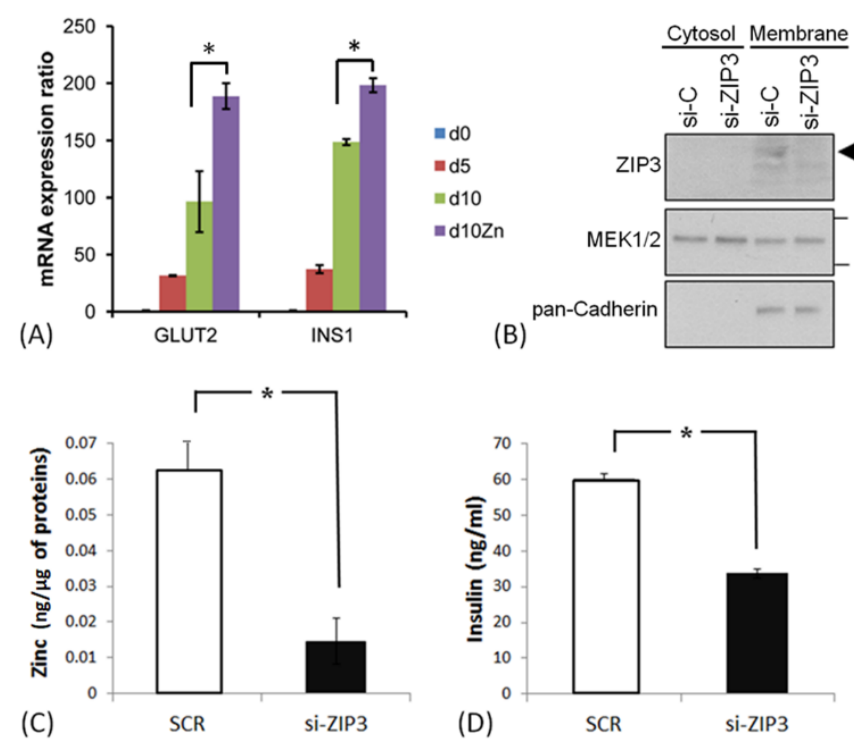

Figure 3. Changes in mRNA levels of GLUT2 and INS1 as SHED cells mature into insulin-producing and -secreting SHED $\beta$-cells. Panel (A) shows mRNA expression of GLUT2 and INS1 at d10 in response to supplementation with $50 \mu \mathrm{M}$ zinc $\left(\mathrm{n}=3,{ }^{*} p<0.01\right)$. (B) Western blot analysis of ZIP3 protein in membrane and cytosol of SHED $\beta$-cells. Arrowhead approximates the position of molecular weight (M.W.) of 34. Note the siRNA knocked down ZIP3 band expression on the right-most column for siZIP3 extracted from the membrane. MEK1/2 are ubiquitous kinase enzymes. Note that pan-Cadherin expresses in the membrane only. (C) Effects of ZIP3 knockdown on zinc levels compared with cells treated with scrambled (SCR) siRNA. (D) Effects of ZIP3 knockdown on insulin secretion compared with cells treated with scrambled (SCR) siRNA. * $p<0.01$. 


\subsection{Supplementation of Zinc during Differentiation Affects GABA-Induced $\mathrm{Ca}^{2+}$ Responses in SHED $\beta$-Cells}

To investigate the effects of zinc on GABA-induced calcium signaling, we investigated the excitability of SHED $\beta$-cells using $\mathrm{Ca}^{2+}$ imaging. We quantified the proportion of randomly selected SHED cells $(n=93)$ and SHED $\beta$-cells $(n=103)$ that responded to $\mathrm{KCl}$ and/or Ach. A change in the Fura signal $(\Delta 340 / 380)$ induced by the stimulus that exceeded the pre-stimulation level by $>15 \%$ was counted as a positive response. We know that differentiation of $\beta$-cells from human embryonic stem cells is accompanied by a KCl-induced increase in intracellular free $\mathrm{Ca}^{2+}$ concentration $\left(\left[\mathrm{Ca}^{2+}\right]_{\mathrm{i}}\right)$, with enhanced expression of voltage-dependent $\mathrm{Ca}^{2+}$ channels (VDCC) [24,25]. Therefore, differentiation of non-excitable SHED cells (Figure 4(Aa)) into SHED $\beta$-cells (Figure 4(Ab)) should be accompanied by functional expression of molecules responsible for $\mathrm{Ca}^{2+}$ signaling. For ratiometric $\mathrm{Ca}^{2+}$ imaging analysis on SHED and SHED $\beta$-cells using the $\mathrm{Ca}^{2+}$-sensitive fluorescent dye Fura-2AM, we used $\mathrm{KCl}$-induced increases in $\left[\mathrm{Ca}^{2+}\right]_{i}$ as a functional marker of excitable SHED $\beta$-cells. When undifferentiated SHED cells were exposed to Ach, approximately $25 \%$ of cells responded by increasing $\left[\mathrm{Ca}^{2+}\right]_{\mathrm{i}}$ (Figure $4(\mathrm{Ac})$ ). When the same SHED cells were exposed to $\mathrm{KCl}$, only $2 \%$ of cells showed a noticeable increase in $\left[\mathrm{Ca}^{2+}\right]_{\mathrm{i}}$. In contrast, a majority of SHED $\beta$-cells $(>60 \%)$ showed robust $\mathrm{Ca}^{2+}$ responses to Ach (Figure 4(Ac), blue segments). Furthermore, SHED $\beta$-cells were more responsive than SHED to $\mathrm{KCl}$ (Figure 4(Ac), red segments). These results showed that differentiation of SHED into SHED $\beta$-cells enhanced Ach- and KCl-induced excitation.
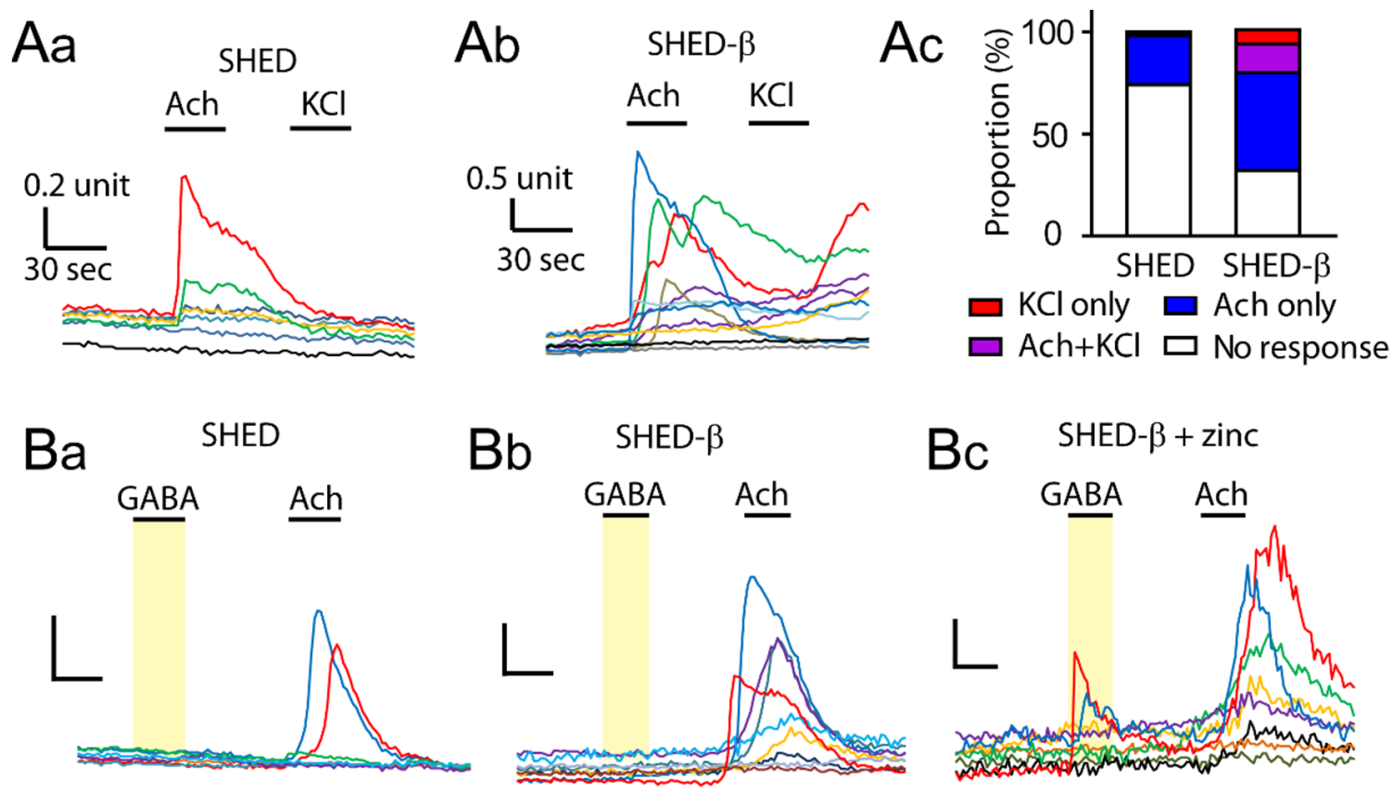

Figure 4. Changes in intracellular calcium levels in SHED $\beta$-cells in response to exogenous GABA challenge. Panel A: Excitation by Ach and $\mathrm{KCl}$ during differentiation of SHED into SHED $\beta$-cells. Representative traces of ratiometric $\mathrm{Ca}^{2+}$ imaging using Fura-2AM in undifferentiated SHED cells (Aa) and differentiated SHED $\beta$-cells $(\mathbf{A b})$ at Day 10 . Each trace represents time-dependent $\left[\mathrm{Ca}^{2+}\right]_{\mathrm{i}}$ changes in each cell. Ach $(100 \mu \mathrm{M})$ and $\mathrm{KCl}(50 \mathrm{mM})$ were superfused during the indicated time. Histogram (Ac) shows quantification of cells responding to $\mathrm{KCl}$ and/or Ach. Panel B: Supplementation of zinc during differentiation affects GABA-induced $\mathrm{Ca}^{2+}$ responses in SHED $\beta$-cells. Examples of traces of $\mathrm{Ca}^{2+}$ imaging in SHED cells (Ba), differentiated SHED $\beta$-cells (Bb), and differentiated SHED $\beta$-cells with zinc supplementation (Bc). GABA $(100 \mu \mathrm{M})$ and Ach $(100 \mu \mathrm{M})$ were superfused during the indicated time. Vertical scale bars represent 0.5 Fura units $(\Delta 340 / 380)$, and horizontal scale bars represent $30 \mathrm{~s}$. 
Next, to investigate interactions between zinc and GABA, we measured the excitability of SHED $\beta$-cells using GABA or GABA plus zinc to stimulate SHED and SHED $\beta$-cells (Figure 4(Ba-c)). The results shown in Figure $4 \mathrm{~B}$ indicate that GABA induced $\mathrm{Ca}^{2+}$ influx in a zinc-dependent manner.

\section{Discussion}

Autocrine regulation of insulin secretion by GABA may not be a primary regulatory mechanism for insulin secretion. Braun et al. [13] previously described the co-secretion of GABA and zinc from $\beta$-cells. They reported that during insulin secretion, $\mathrm{GABA}_{\mathrm{A}}$ receptors in human $\beta$-cells enhanced membrane depolarization, increasing $\left[\mathrm{Ca}^{2+}\right]_{i}$ when $\mathrm{GABA}$ was coupled with $\mathrm{GABA}_{\mathrm{A}}$ receptors, as if the coupling may be a "redundant" secretion pathway. In the current study, we have shown that both extracellular GABA and zinc influence insulin secretion through membrane depolarization when ZIP3 levels are "optimal" in SHED $\beta$-cells. These results are consistent with a recent report describing GABAergic regulation of the antidiabetic effects of exogenous supplementation with GABA or GABAergic drugs [14].

A known apparatus of depolarization-induced $\mathrm{Ca}^{2+}$ influx in pancreatic $\beta$-cells is VDCC. Given that application of a high concentration of extracellular $\mathrm{KCl}$ to insulin-secreting cells is well known to induce $\mathrm{Ca}^{2+}$ influx, $[25,26]$ we used $\mathrm{KCl}$-induced increases in $\left[\mathrm{Ca}^{2+}\right]_{\mathrm{i}}$ as a functional marker for excitable SHED $\beta$-cells. GABA is co-secreted with insulin molecules from $\beta$-cells $[13,16]$. Unlike the hyperpolarizing effects of GABA in the central nervous system, GABA initiates membrane depolarization followed by $\left[\mathrm{Ca}^{2+}\right]_{\mathrm{i}}$ elevation in pancreatic $\beta$-cells. Therefore, we used the GABA-induced $\mathrm{Ca}^{2+}$ increase as a unique marker of excitable SHED $\beta$-cells. Our experiments showed that $\mathrm{Ca}$-influx in response to GABA was only observed in SHED $\beta$-cells in the presence of added zinc and was not seen in undifferentiated SHED cells in response to GABA irrespective of added zinc.

Our previous study demonstrated that insulin production is proportional to cytosolic zinc levels [10]. As the cytosolic zinc concentration decreased, a corresponding amount of insulin production by the cells decreased as well. A previous study using patch clamp experiments demonstrated that extracellular concentrations of zinc ions could control insulin secretion via controlling ATP-sensitive potassium channels [27]. Yet, no zinc transporters were measured in their report. Our older study ${ }^{9}$ using primary rodent islets, as well as the present study, noted that cytosolic zinc levels regulated by ZIP transporters interact with other chloride ion exchangers such as $\mathrm{GABA}_{\mathrm{A}}$ receptors in insulin homeostasis. If effects of zinc ions on insulin secretion functionally interact with other molecular actions such as GABA-GABA $A_{A}$ receptor coupling, it could provide a reason for the limited success of therapeutic zinc supplementation seen in human clinical studies [28,29]. To maintain effective cytosolic zinc levels, our findings indicate that $\beta$-cells require maintenance of functional zinc uptake transporters.

\section{Conclusions}

Our results suggest that zinc enhances GABA-induced calcium influx in SHED $\beta$-cells through a coupling action of GABA with $\mathrm{GABA}_{\mathrm{A}}$ receptor subunits; thus, $\mathrm{GABA}_{\mathrm{A}}$ receptors in the membrane of SHED $\beta$-cells are functional. Yet, in zinc-pretreated SHED $\beta$-cells, exogenous GABA elevates $\mathrm{Ca}^{2+}$ influx, whereas in the absence of added zinc, GABA alone does not. Thus, there may be a functional difference between primary pancreatic $\beta$-cells and SHED-derived $\beta$-cells. This study suggests that SHED may provide a source of insulin production if SHED function is augmented via the interaction between zinc and GABA.

Author Contributions: Conceptualization, E.-K.P.; methodology, G.K., M.-K.C., E.-K.P.; analyses, G.K., M.-K.C.; data curation, G.K., M.-K.C., E.-K.P.; original draft, E.-K.P.; review and editing, M.-K.C., E.-K.P.; visualization, M.-K.C., G.K.; supervision, E.-K.P.; project administration, E.-K.P. All authors have read and agreed to the published version of the manuscript.

Funding: This research received no external funding.

Conflicts of Interest: The authors declare no conflict of interest. 


\section{References}

1. Rickels, M.R.; Robertson, R.P. Pancreatic Islet Transplantation in Humans: Recent Progress and Future Directions. Endocr. Rev. 2019, 40, 631-668. [CrossRef]

2. Gamble, A.; Pepper, A.R.; Bruni, A.; Shapiro, A.M.J. The journey of islet cell transplantation and future development. Islets 2018, 10, 80-94. [CrossRef]

3. De Leon-Rodriguez, L.; Lubag, A.J., Jr.; Sherry, A.D. Imaging free zinc levels In Vivo-What can be learned? Inorg. Chim. Acta 2012, 393, 12-23. [CrossRef] [PubMed]

4. Chu, A.; Foster, M.; Hancock, D.; Petocz, P.; Samman, S. Interrelationships among mediators of cellular zinc homeostasis in healthy and type 2 diabetes mellitus populations. Mol. Nutr. Food Res. 2017, 61. [CrossRef] [PubMed]

5. Wijesekara, N.; Chimienti, F.; Wheeler, M.B. Zinc, a regulator of islet function and glucose homeostasis. Diabetes Obes. Metab. Suppl. 2009, 4, 202-214. [CrossRef] [PubMed]

6. Dufner-Beattie, J.; Huang, Z.L.; Geiser, J.; Xu, W.; Andrews, G.K. Mouse ZIP1 and ZIP3 genes together are essential for adaptation to dietary zinc deficiency during pregnancy. Genesis 2006, 44, 239-251. [CrossRef]

7. Slepchenko, K.G.; Li, Y.V. Rising intracellular zinc by membrane depolarization and glucose in insulin-secreting clonal HIT-T15 beta cells. Exp. Diabetes Res. 2012, 190309. [CrossRef]

8. Slepchenko, K.G.; Daniels, N.A.; Guo, A.; Li, Y.V. Autocrine effect of $\mathrm{Zn}^{2+}$ on the glucose-stimulated insulin secretion. Endocrine 2015, 50, 110-122. [CrossRef]

9. Pae, E.K.; Kim, G. Insulin production hampered by intermittent hypoxia via impaired zinc homeostasis. PLoS ONE 2014, 9, e90192. [CrossRef]

10. Kim, G.; Shin, K.H.; Pae, E.K. Zinc Up-Regulates Insulin Secretion from $\beta$ Cell-Like Cells Derived from Stem Cells from Human Exfoliated Deciduous Tooth (SHED). Int. J. Mol. Sci. 2016, 17, 2092. [CrossRef]

11. Shin, J.S.; Kim, J.M.; Min, B.H.; Chung, H.; Park, C.G. Absence of spontaneous regeneration of endogenous pancreatic $\beta$-cells after chemical-induced diabetes and no effect of GABA on $\alpha$-to- $\beta$ cell transdifferentiation in rhesus monkeys. Biochem. Biophys. Res. Commun. 2019, 508, 1056-1061. [CrossRef] [PubMed]

12. Yi, Z.; Waseem Ghani, M.; Ghani, H.; Jiang, W.; Waseem Birmani, M.; Ye, L.; Bin, L.; Cun, L.G.; Lilong, A.; Mei, X. Gimmicks of gamma-aminobutyric acid (GABA) in pancreatic $\beta$-cell regeneration through transdifferentiation of pancreatic $\alpha$ - to $\beta$-cells. Cell Biol. Int. 2020, 44, 926-936. [CrossRef] [PubMed]

13. Braun, M.; Ramracheya, R.; Rorsman, P. Autocrine regulation of insulin secretion. Diabetes Obes. Metab.'Suppl. 2012, 3, 143-151. [CrossRef] [PubMed]

14. Wang, Q.; Ren, L.; Wan, Y.; Prud'homme, G.J. GABAergic regulation of pancreatic islet cells: Physiology and antidiabetic effects. J. Cell. Physiol. 2019. [CrossRef]

15. Untereiner, A.; Abdo, S.; Bhattacharjee, A.; Gohil, H.; Pourasgari, F.; Ibeh, N.; Lai, M.; Batchuluun, B.; Wong, A.; Khuu, N.; et al. GABA promotes $\beta$-cell proliferation, but does not overcome impaired glucose homeostasis associated with diet-induced obesity. FASEB J. 2019, 33, 3968-3984. [CrossRef]

16. Bansal, P.; Wang, S.; Liu, S.; Xiang, Y.Y.; Lu, W.Y.; Wang, Q. GABA coordinates with insulin in regulating secretory function in pancreatic INS-1 $\beta$-cells. PLoS ONE 2011, 6, e26225. [CrossRef]

17. Braun, M.; Ramracheya, R.; Bengtsson, M.; Clark, A.; Walker, J.N.; Johnson, P.R.; Rorsman, P. Gamma-aminobutyric acid (GABA) is an autocrine excitatory transmitter in human pancreatic beta-cells. Diabetes 2010, 59, 1694-1701. [CrossRef]

18. Yu, T.; Jiang, Z.; Liu, L.; Fan, Z. Decrease of $\gamma$-aminobutyric acid and zinc ions in the islet periportal circulation stimulates glucagon secretion during hypoglycemia. Exp. Ther. Med. 2018, 15, 2507-2511. [CrossRef]

19. Jeong, J.; Eide, D.J. The SLC39 family of zinc transporters. Mol. Asp. Med. 2013, 34, 612-619. [CrossRef]

20. Wijesekara, N.; Dai, F.F.; Hardy, A.B.; Giglou, P.R.; Bhattacharjee, A.; Koshkin, V.; Chimienti, F.; Gaisano, H.Y.; Rutter, G.A.; Wheeler, M.B. Beta cell-specific Znt8 deletion in mice causes marked defects in insulin processing, crystallisation and secretion. Diabetologia 2010, 53, 1656-1668. [CrossRef]

21. Govindasamy, V.; Ronald, V.S.; Abdullah, A.N.; Nathan, K.R.; Ab Aziz, Z.A.; Abdullah, M.; Musa, S.; Kasim, N.H.; Bhonde, R.R. Differentiation of dental pulp stem cells into islet-like aggregates. J. Dent. Res. 2011, 90, 646-652. [CrossRef] [PubMed]

22. Chung, M.K.; Lee, H.; Caterina, M.J. Warm temperatures activate TRPV4 in mouse 308 keratinocytes. J. Biol. Chem. 2003, 22, 32037-32046. [CrossRef] [PubMed] 
23. Wang, S.; Joseph, J.; Ro, J.Y.; Chung, M.K. Modality-specific mechanisms of protein kinase C-induced hypersensitivity of TRPV1: S800 is a polymodal sensitization site. Pain 2015, 156, 931-941. [CrossRef] [PubMed]

24. Gyulkhandanyan, A.V.; Lee, S.C.; Bikopoulos, G.; Dai, F.; Wheeler, M.B. The $\mathrm{Zn}^{2+}$-transporting pathways in pancreatic beta-cells: A role for the L-type voltage-gated $\mathrm{Ca}^{2+}$ channel. J. Biol. Chem. 2006, 281, 9361-9372. [CrossRef]

25. Henquin, J.C.; Dufrane, D.; Gmyr, V.; Kerr-Conte, J.; Nenquin, M. Pharmacological approach to understanding the control of insulin secretion in human islets. Diabetes Obes. Metab. 2017, 19, 1061-1070. [CrossRef]

26. Taylor, J.T.; Huang, L.; Keyser, B.M.; Zhuang, H.; Clarkson, C.W.; Li, M. Role of high-voltage-activated calcium channels in glucose-regulated beta-cell calcium homeostasis and insulin release. Am. J. Physiol. Endocrinol. Metab. 2005, 289, E900-E908. [CrossRef]

27. Bloc, A.; Cens, T.; Cruz, H.; Dunant, Y. Zinc-induced changes in ionic currents of clonal rat pancreatic-cells: Activation of ATP-sensitive $\mathrm{K}^{+}$channels. J. Physiol. 2000, 529, 723-734. [CrossRef]

28. Capdor, J.; Foster, M.; Petocz, P.; Samman, S. Zinc and glycemic control: A meta-analysis of randomised placebo-controlled supplementation trials in humans. J. Trace Elem. Med. Biol. 2013, 27, 137-142. [CrossRef]

29. Myers, S.A.; Nield, A.; Myers, M. Zinc transporters, mechanisms of action and therapeutic utility: Implications for type 2 diabetes mellitus. J. Nutr. Metab. 2012, 173712. [CrossRef]

Publisher's Note: MDPI stays neutral with regard to jurisdictional claims in published maps and institutional affiliations. 